\title{
First Detection of Augmentin and Colistin Resistant Cronobacter Sakazakii from a Pharmaceutical Wastewater in South-Western Nigeria
}

\author{
Avemaria Obasi", Simon Cyril Nwachukwu, Esther Ugoji \\ Department of Microbiology, University of Lagos, Lagos, Nigeria \\ Email address: \\ avemariaobasi@yahoo.com (A. Obasi), simoncyril@yahoo.om (S. C. Nwachukwu), ugojie@gmail.com (E. Ugoji) \\ ${ }^{*}$ Corresponding author
}

To cite this article:

Avemaria Obasi, Simon Cyril Nwachukwu, Esther Ugoji. First Detection of Augmentin and Colistin Resistant Cronobacter Sakazakii from a Pharmaceutical Wastewater in South-Western Nigeria. American Journal of Chemical and Biochemical Engineering.

Vol. 2, No. 1, 2018, pp. 1-9. doi: 10.11648/j.ajcbe.20180201.11

Received: May 8, 2018; Accepted: May 29, 2018; Published: June 12, 2018

\begin{abstract}
Cronobacter sakazakii formerly known as Enterobacter sakazakii, is a bacterium with a rare cause but often fatal infection of the bloodstream and central nervous system. Infants with weakened immune systems, particularly premature infants, are most likely to contact a Cronobacter infection, although the bacteria have caused illnesses in all age groups. Most cases of $C$. sakazakii infection come from powdered infant formula (PIF) contaminated with the bacterium. Although relatively little information is known about the existence of Cronobacter in the environment, more reservoirs are being identified, such as water, soil and plant material. Wastewaters from 6 pharmaceutical industries located in a south-western state in Nigeria were sampled and analyzed. Bacteria were isolated using standard methods and species identification was determined by Gram staining, lactose fermentation, oxidase, catalase and Vitek 2. Antibacterial susceptibility to 25 antimicrobial agents was tested by the disc diffusion method and Vitek 2. Fifty nine Gram-negative bacteria were isolated and identified; one was identified as C. sakazakii. The bacterium was susceptible to all antibiotic mentioned but resistant to augmentin (amoxicillin/clavulanate) and colistin which are high potent drugs for the treatment of very stubborn infections. The public health implication of this fact is that this bacterium could be harbouring resistant genes that can be transferred through water ways such as the pharmaceutical wastewaters to bacteria of the same or different species of clinical importance. Therefore, continuous surveillance of the environmental reservoirs of antibiotic resistant bacteria is necessary to prevent their further spread.
\end{abstract}

Keywords: C. Sakazakii, Colistin, Augmentin, Pharmaceutical Wastewater

\section{Introduction}

Cronobacter is a genus of Gram-negative, facultatively anaerobic, oxidase-negative, catalase-positive, rod-shaped bacteria of the family Enterobactereiaceae. The genus Cronobacter has been divided into seven species: Cronobacter sakazakii, Cronobacter malonaticus, Cronobacter turicensis, Cronobacter muytjensii, Cronobacter dublinensis, Cronobacter universalis and Cronobacter condimenti [1-3]. Among them, C. sakazakii is considered as the predominant species associated with neonatal infections [4].

Clinical manifestation of Cronobacter infections have been associated most frequently with sporadic cases of lifethreatening illness, in particular meningitis, necrotizing enterocolitis (NEC) and septicemia in infants [5]. Low birthweight neonates (i.e. $<2.5 \mathrm{~kg}$ ) and infants $<28$ days of age are at heightened risk compared to more mature infants [6-9]. Symptoms include meningitis leading to ventriculitis, brain abscess, hydrocephalus and cyst formation as well as NEC characterized by intestinal necrosis and pneumatosis intestinalis; pulmonary, urinary and blood stream infections $[10,11]$. In infants, meningital Cronobacter infection is established between the fourth and fifth days post birth and can be fatal within hours to several days following the onset of first clinical symptoms [12]. The mortality rate for neonatal infections has been reported to be as high as $80 \%[5$, 10] and survivors often suffer from severe irreversible neurological disorders. Reports of invasive infections with Cronobacter in adults are rare, although there have been a 
few accounts of illness among the immunocompromised [5].

In previous reports, C. sakazakii isolates were genotyped into 14 STs by multilocus sequence typing (MLST), among them, C. sakazakii ST4 was the main sequence type of Cronobacter species, and was associated with neonatal meningitis [4, 13, 14]. Meanwhile, C. sakazakii isolates belonging to ST4 had a stronger ability to resistance to desiccation than ST1, ST8, ST12, ST21, ST64, ST201, and ST258, which may be one of reasons that ST4 was the main sequence type recovered from PIF [15]. C. sakazakii ST83 is another major sequence type with a strong capacity to resistance to desiccation in PIF factories [16]. C. sakazakii ST1 is reported to be a major sequence type of strains from PIF, while C. sakazakii ST8 strains are primarily isolated from clinical sources [17]. In addition, C. sakazakii ST12 can infect neonates and infants to suffer from necrotizing enterocolitis (4). The C. sakazakii strains with these STs have been isolated from commercial PIF, which suggests that ST4, ST1, ST8, ST12, and ST83 should be more risk for neonates and infants.

Currently, antibiotic therapy is the most common and effective method to treat Cronobacter infections [18]. Antibiotics are extremely important in medicine, but more and more bacteria develop resistance to various antimicrobial substances. Drug-resistant bacteria existed long before humans began using antibiotics therapeutically, but the extensive use or misuse of antibiotics selects resistant strains that spread worldwide. Exposure of environmental bacteria to antibiotics as well as to large numbers of resistant bacteria may fast-track the evolution of resistance, increase the profusion and dissemination of resistance genes within the resistome that is precarious to the development of clinical resistance, and increase exchange of antibiotic resistance genes between bacteria [19, 20]. Because most Enterobacter species are either very resistant to many agents or can develop resistance during antimicrobial therapy, the choice of appropriate antimicrobial agents is complicated. A majority of Cronobacter species strains are reported to be susceptible to frequently-used antibiotics, however, long-term use or abuse of antibiotics is likely to lead to the development of Cronobacter antibiotic resistance $[21,22]$.

Despite the ubiquity of Cronobacter in the food supply, there is a close association with PIF [23]. In epidemiological studies, [24] examined 141 different breast milk substitute powders from 35 countries and enumerated Cronobacter from 20 samples; another study in Canada also isolated Cronobacter from eight of 120 samples of PIF from five different manufacturers [25]. In the United Kingdom, [26] reported that, out of 84 PIF samples from retailers, 2 were positive for Cronobacter. In addition, [27] applied pulsed field gel electrophoresis to trace the prevalence of Cronobacter in an infant formula processing facility and found that the manufacturing environment serves as a primary route for sporadic contamination of PIF [23]. It is therefore perceived that there is limited information on the prevalence of Cronobacter in water resources.
In recent times, concerns on the effects of pharmaceutical wastewaters on the environment are becoming worrisome, as studies by [28] showed that the physico-chemical analysis revealed the presence of constituents capable of inducing mutations in biological systems, and suggested that the tested pharmaceutical effluent is a potent clastrogenic and mutagenic agent and hence are potential adverse health risk to exposed living organisms. One of the ways in which bacteria acquire resistance to antibiotics is due to selective pressure as a result of human activities, and water plays an important role in the dissemination of these organisms among humans, animals and the environment. Antibiotic-resistant pathogens are profoundly important to human health, but the environmental reservoirs of resistance determinants are poorly understood. There are strict regulations in developed countries on issues concerning treatment of wastewaters before discharge. However, due to ignorance, poverty and lack of monitoring by regulatory bodies on environmental issues in most African countries, such as Nigeria, these are not adequate. Reports by [29] on the lack of treatment measures of pharmaceutical wastewaters before disposal into lakes and rivers in Nigeria could result in the prevalence of antibiotic-resistance bacteria and the dissemination of ARG in wastewaters emanating from pharmaceutical industries in Nigeria. What needs to be done is not to try to defeat the resistance itself, but to try to minimize the spread of it. This means that constant monitoring of the usage and possible emissions of antibiotics is needed in order to reduce environmental risk as much as possible. Therefore, there is need to investigate antibiotic resistant bacteria such as $C$. sakazakii present in wastewaters from pharmaceutical industries in Nigeria as a surveillance strategy for epidemiological studies. This study was aimed at isolating and identifying $C$. sakazakii from pharmaceutical wastewaters in Nigeria and to determine the antibiotic resistance profile of the bacteria.

\section{Methods}

\subsection{Wastewaters Sampling Sites}

Wastewater samples $(\mathrm{n}=18)$ were collected from discharge points from 6 pharmaceutical industries located in South-western Nigeria. The Global Positioning System (GPS) readings were taken for every sample location (FDO N06 $42133.1^{\prime \prime}$, E003 141 19.8"; NGO - N06 431 08.7", E003 131 21.4"; DFO - N06 421 19.7”, E003 $13144.3^{\prime \prime}$; FAO - N06 431 18.4”, E003 131 21.3"; UNO - N06 431 11.5", E003 $13122.9^{\prime \prime}$; WTO - N06 42133.1 ", E003 141 $\left.19.8^{\prime \prime}\right)$. These chosen sampling sites are known basically for the manufacturing of antibiotics in addition to few other drugs. During and after the manufacturing process, the generated wastewaters are discharged directly (without pretreatment) into local rivers and lakes where human activities take place. This act of lack of consideration for risk assessment strategies and public health implications is worrisome. 


\subsection{Wastewaters Sampling Technique}

The wastewater samples were each initially introduced directly into a $1.5 \mathrm{~L}$ sterile plastic bottle and rinsed twice with the wastewater sample before finally introducing it into the plastic bottle. The wastewaters were filled to about three quarter of the sterile plastic containers to allow space for oxygen, so that microaerophilic organisms can survive before capping up the bottle. The wastewater samples were preserved on ice packs contained in a flask and then taken immediately to the laboratory for routine microbiological analysis. Samples were processed immediately or stored at $4^{\circ} \mathrm{C}$ until use. Visit to each pharmaceutical industry for the collection of wastewaters was done three times during the period of sampling. The sampling period was for one year, May 2011 to May 2012.

\subsection{Isolation and Identification of Bacteria}

Bacteria were isolated on MacConkey agar and Gramstaining performed using standard methods according to the method of [30] as preliminary identification test. Motility test was demonstrated by the method described by [31] Biochemical tests such as lactose fermentation, catalase and oxidase tests were also carried out to further confirm the identity of the bacteria [32]. Final confirmatory species identification was carried out using the Vitek 2 automated method [33].

\subsection{Antimicrobial Susceptibility Testing}

Antibiotic susceptibility was done with the use of Vitek 2 automated method with cards AST-N223 (Ref. 413110) and AST-N248 (Ref. 413397) including 25 antibiotics: ampicillin, ampicillin/sulbactam, piperacillin, piperacillin/tazobactam, aztreonam, cefotaxime, cefpodoxime, ceftazidime, cefuroxime, cefuroxime/axetil, cefepim, ertapenem, imipenem, meropenem, ciprofloxacin, levofloxacin, moxifloxacin, gentamicin, augmentin (amoxicillin-clavulanate), tobramycin, amikacin, tigecycline, colistin, fosfomycin and trimethroprim/sulfamethoxazole belonging to 10 classes [33]. The disc diffusion method by Kirby Bauer was also utilized for the susceptibility test [34]. Two control strains (Escherichia coli ATCC 25922 and Klebsiella pneumoniae ATCC BAA-1705) were used to validate the measurement. Results were interpreted according to recommendations of the European Committee on Antimicrobial Susceptibility Testing [35].

\section{Results}

\subsection{Isolation and Identification of Bacteria}

Gram-negative bacteria were identified by the pinkish coloration of the bacterial cells when viewed under the microscope. A total number of 59 Gram-negative bacterial isolates from the wastewater samples were obtained and cellular morphology showed that they were all bacilli (rod shaped bacteria). C. sakazakii identified was motile as it spreads throughout the medium in a swarming movement most probably achieved due to it being peritritously flagellated, further confirming its identity. Its colonial morphologies on columbia agar appeared as tiny round with mucoid consistency and creamy to light yellow in colour; ferment lactose on macConkey as shown by the pink colouration of colonies on plate, catalase positive and oxidase negative. Analysis of Gram-negative bacterial diversity of the various pharmaceutical industries wastewater samples revealed presence of 17 different bacterial spp. A single $C$. sakazakii was identified from an industry among other bacteria as well identified in the same industry such as Klebsiella pneumoniae, Burkholderia cepacia group, Pseudomonas aeruginosa, Serratia marcescens and Alcaligenes faecalis. The Vitek 2 biochemical details for the identification of $C$. sakazakii is shown in Table 1.

Table 1. Biochemical Details for Vitek 2 Identification for C. sakazakii.

\begin{tabular}{|c|c|c|c|}
\hline Test (Abbreviation) & Test (sugars) & Qty (mg) & Cronobacter sakazaki group (94\%) \\
\hline APPA & Ala-Phe-Pro-ARYLAMIDASE & 0.0384 & - \\
\hline ADO & ADONITOL & 0.1875 & - \\
\hline PyrA & L-Pyrroolydonyl-ARYLAMIDASE & 0.018 & - \\
\hline IARL & L-ARABITOL & 0.3 & - \\
\hline $\mathrm{dCEL}$ & D-CELLOBIOSE & 0.3 & + \\
\hline BGAL & BETA-GALACTOSIDASE & 0.036 & + \\
\hline BNAG & BETA-N-ACETYL-GLUCOSAMIDASE & 0.0408 & + \\
\hline AGLTp & Glutamyl-Arylamidase-pNA & 0.0324 & - \\
\hline dGLU & D-GLUCOSE & 0.3 & + \\
\hline GGT & GAMMA-GLUTAMYL-TRANSFERASE & 0.0228 & - \\
\hline OFF & FERMENTIERUNG/GLUCOSE & 0.45 & - \\
\hline BGLU & BETA-GLUCOSIDASE & 0.036 & + \\
\hline dMAL & D-MALTOSE & 0.3 & + \\
\hline dMNE & D-MANNOSE & 0.3 & + \\
\hline BXYL & BETA-XYLOSIDAE & 0.0324 & + \\
\hline BAlap & BETA-Alanin-Arylamidase-pNA & 0.0174 & - \\
\hline
\end{tabular}




\begin{tabular}{|c|c|c|c|}
\hline Test (Abbreviation) & Test (sugars) & Qty (mg) & Cronobacter sakazaki group (94\%) \\
\hline ProA & L-Proline-ARYLAMIDASE & 0.0234 & - \\
\hline LIP & LIPASE & 0.0192 & - \\
\hline PLE & PALATINOSE & 0.3 & + \\
\hline TyrA & Tyrosin-ARYLAMIDASE & 0.0276 & + \\
\hline URE & UREASE & 0.15 & - \\
\hline dSOR & D-SORBIT & 0.1875 & - \\
\hline SAC & SACCHAROSE/SUCROSE & 0.3 & + \\
\hline dTAG & D-TAGATOSE & 0.3 & - \\
\hline dTRE & D-TREHALOSE & 0.3 & + \\
\hline CIT & CITRAT (NATRIUM) & 0.054 & - \\
\hline MNT & MALONAT & 0.15 & - \\
\hline $5 \mathrm{KG}$ & 5-KETO-D-GLUCONAT & 0.3 & - \\
\hline ILATk & L-LACTATE & 0.15 & - \\
\hline AGLU & ALPHA-GLUCOSIDASE & 0.036 & + \\
\hline SUCT & SUCCINATE & 0.15 & - \\
\hline NAGA & Beta-N-ACETYL-GALACTOSAMINIDASE & 0.0306 & - \\
\hline AGAL & ALPHA-GALACTOSIDASE & 0.036 & + \\
\hline PHOS & PHOSPHATASE & 0.0504 & - \\
\hline GlyA & Glycin-ARYLAMIDASE & 0.012 & - \\
\hline ODC & ORNITHIN-DECARBOXYLASE & 0.3 & - \\
\hline LDC & DECARBOXYLASE-BASIS & 0.15 & - \\
\hline IHISa & L-HISTIDINE-Assimilation & 0.087 & - \\
\hline CMT & COURMARAT & 0.126 & - \\
\hline BGUR & BETA-GLUCORONIDASE & 0.0378 & $(+)$ \\
\hline O129R & 0/129-RESISTANCE (Comp. vibrio) & 0.0105 & - \\
\hline GGAA & Glu-Gly-Arg-ARYLAMIDASE & 0.0576 & - \\
\hline IMLTa & L-MALATE-Assimilation & 0.042 & - \\
\hline ELLM & ELLMAN & 0.03 & + \\
\hline ILATa & L-LACTATE-Assimilation & 0.186 & - \\
\hline
\end{tabular}

\subsection{Antimicrobial Susceptibility Testing}

The analysis of the pattern of resistance to the 25 antibiotics observed in C. sakazakii showed that this bacterium was susceptible to ampicillin, ampicillin/sulbactam, piperacillin, piperacillin/tazobactam, aztreonam, cefotaxime, cefpodoxime, ceftazidime, cefuroxime, cefuroxime/axetil, cefepim, ertapenem, imipenem, meropenem, ciprofloxacin, levofloxacin, moxifloxacin, gentamicin, tobramycin, amikacin, tigecycline, fosfomycin and trimethroprim/sulfamethoxazole. However, in contrast to earlier observation, this same $C$. sakazakii isolate was resistant to augmentin (amoxicillin/clavulanate) and colistin (Table 2), which are high potent antibiotics used for the treatment of clinical infections or in combination therapy sometimes as last line of drugs in the treatment of very stubborn infections. The MIC values for the breakpoint for resistance in $C$. sakazakii ranges from $\leq 1$ for gentamycin to $\geq 320$ for trimethroprim/sulfamethoxazole while the value for susceptibility ranges from $\leq 0.5$ for meropenem to 4 for cefuroxime. The disc diffusion method as shown on plate presents the susceptibility pattern of the bacterial isolate with few antibiotics for a clear demonstration of a phenotypic representation of resistance and susceptible as the case may be (Figure 1).

Table 2. Antimicrobial Susceptibility pattern of C. sakazakii from a pharmaceutical Wastewater.

\begin{tabular}{ll}
\hline Antimicrobial agent & Susceptibility \\
\hline Ampicillin (AMP) & $\mathrm{S}$ \\
Ampicillin/sulbactam (SAM) & $\mathrm{S}$ \\
Piperacillin (PIP) & $\mathrm{S}$ \\
Piperacillin/tazobactam (TZP) & $\mathrm{S}$ \\
Cefuroxime (CXM) & $\mathrm{S}$ \\
Cefuroxime/axetil (ACE) & $\mathrm{S}$ \\
Cefpodoxime (CPD) & $\mathrm{S}$ \\
Cefotaxime (CTX) & $\mathrm{S}$ \\
Ceftazidime (CAZ) & $\mathrm{S}$ \\
Ertapenem (ERT) & $\mathrm{S}$ \\
Imipenem (IPM) & $\mathrm{S}$ \\
Meropenem (MEM) & $\mathrm{S}$ \\
Gentamicin (GEN) & $\mathrm{S}$ \\
Ciprofloxacin (CIP) & $\mathrm{S}$ \\
Moxifloxacin (MXF) & $\mathrm{S}$ \\
Levofloxacine (LEV) & $\mathrm{S}$ \\
\hline
\end{tabular}




\begin{tabular}{ll}
\hline Antimicrobial agent & Susceptibility \\
\hline Tigecycline (TGC) & $\mathrm{S}$ \\
Cefepim (FEP) & $\mathrm{S}$ \\
Aztreonam (ATM) & $\mathrm{S}$ \\
Amikacin (AMK) & $\mathrm{S}$ \\
Tobramycin (TOB) & $\mathrm{S}$ \\
Fosfomycin (FOS) & $\mathrm{S}$ \\
Colistin (COL) & $\mathrm{R}$ \\
Sulfamethoxazole/Trimethoprim (SXT) & $\mathrm{S}$ \\
Augmentin \{Amoxicilin/Clavulanate\}(AMC) & $\mathrm{R}$ \\
\hline
\end{tabular}

S, Susceptible; R, Resistant.

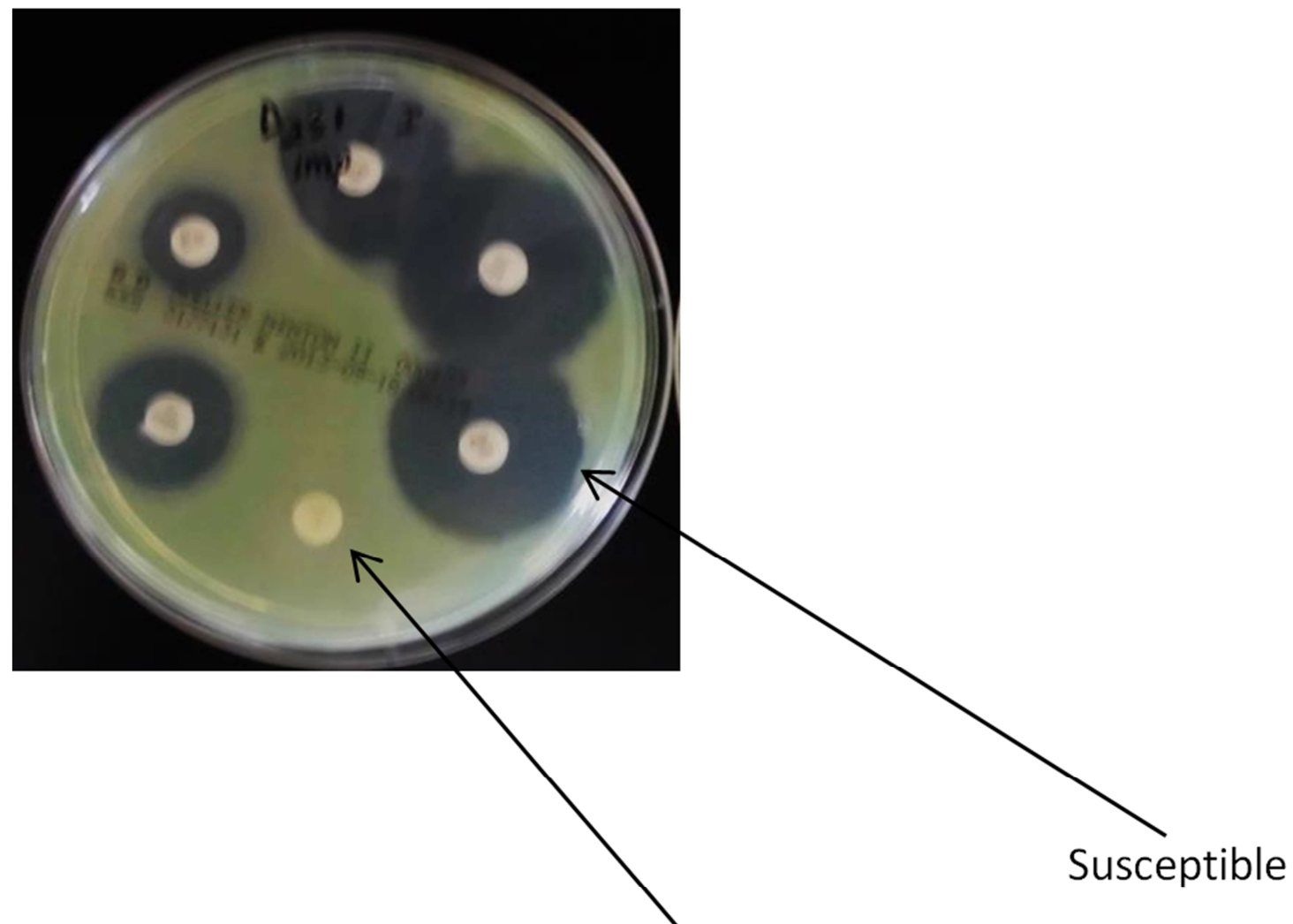

\section{Resistant}

Figure 1. C. sakazakii susceptibility to antibiotic displayed on Mueller-hington agar plate.

\section{Discussion}

Wastewaters in mega cities are notorious reservoirs of microbial pathogens; through the production of biofilms. Wastewater effluent systems represent a protective niche for commensals and pathogens favouring the horizontal transfer of genes encoding for resistance factors [36]. In order to analyse the bacterial contamination and presence of clinically relevant antibiotic resistance, wastewaters from 6 pharmaceutical industries were investigated.

Isolation and identification of bacteria from these pharmaceutical wastewaters apparently revealed the diversity of different bacteria in the wastewater environment. Wastewater samples from one industry had appreciable representation of diverse organisms identified, including antibiotic resistant C. sakazakii. Although much has been said about their presence in PIF [23-27]. The results obtained in the identification technique for this bacterium conformed to that obtained by [37] in their study as well, where the cultural, cellular and biochemical tests examined in their report on 'the documentation of a new species of E. sakazakii now called C. sakazakii' are in tune with our result also (Table 1).

The antibiotic resistance mechanisms of bacteria are diverse; changes of the antibiotic target molecules lead to resistance or the antibiotics were inactivated or neutralized by different biochemical modifications. Active export of antibiotics or the loss of distinct outer membrane proteins (porins) can also reduce the antimicrobial susceptibility. Many antibiotic resistance genes are transferable and can be spread successfully in various bacterial species. The clinical failure of antimicrobial drugs that were previously effective in controlling infectious disease is a tragedy of increasing 
magnitude that gravely affects human health. The emergence and dissemination of antimicrobial resistance are well established as clinical problems that affect human and animal health [38, 39].

The antibiotic susceptibility patterns of the 59 Gramnegative bacterial isolates in this study showed that there were single, double and multiple resistance phenotypes, however the antibiotic susceptibility test results for the only C. sakazakii isolate from the pharmaceutical wastewater showed that it has double resistance phenotype susceptible to all other antibiotics except for amoxicillin-clavulanate and colistin. In a study by [15], antibiotic profile of $56 \mathrm{C}$. sakazakii strains isolated from PIF in China retail markets showed that all C. sakazakii isolates were susceptible to ampicillin-sulbactam, cefotaxime, ciprofloxacin, meropenem, tetracycline, piperacillin-tazobactam, and trimethoprimsulfamethoxazole. The majority of C. sakazakii strains were susceptible to chloramphenicol and gentamicin, with sensitive rates of 87.5 and $92.9 \%$, respectively. In contrast, most C. sakazakii strains were resistant to cephalothin, with resistance and intermediate rates of 55.4 and $41.0 \%$, respectively. Other reports also confirmed that Cronobacter strains resistant to amoxicillin-clavulanate, ampicillin, cefazolin, cephalothin, cefotaxime, and streptomycin have been isolated from food samples [15] and [40-44], which was similar to the result obtained for amoxicillin-clavulanate resistant C. sakazakii in our study. In addition, it is observed that colistin resistance in C. sakazakii in this study seems to be the first report of colistin resistant C. sakazakii, as previous reports were not indicative of this fact. Therefore, it was necessary to evaluate the antibiotic resistance profile of Cronobacter species isolated from other environment such as in a pharmaceutical wastewater.

Treatment options for Cronobacter infection include newer options like tigecycline which has an excellent in vitro activity against these gram-negative bacilli [45]. Although older options which might include intravenous administration of polymyxin B or colistin are drugs that are now rarely used [45]. This statement is justified due to the fact that the bacteria might be fast developing resistance to colistin, like was observed in the strain of $C$. sakazakii isolated from the wastewater from our study. In addition, traditionally, antibiotic therapy with a combination of ampicillin and gentamycin has been successful in treatment of Cronobacter infection [5]. However, optimal antibiotic treatment regimens still need to be determined and the emergence of strains resistant to ampicillin has led to consideration of use of the newer cephalosporins [46] and possible combination therapy. In the light of this, [47] reported that colistin or polymyxin B or tigecycline combined with carbapenem were the most commonly used combination for the treatment of KPC infection when treatment failures were observed in monotherapy as compared with combination therapy, resulting to improved survival. Also a combination therapy with rifampicin and colistin for CRE Acinetobacter baumannii infection was also reported [47]. In addition, this could also imply that $C$. sakazakii resistant to colistin isolated from a pharmaceutical wastewater calls for concern as treatment failures to certain infections might be imminent, especially if resistance determinants are widely spread in wastewaters which can be disseminated from non-pathogenic strains into their pathogenic counterparts.

The extent to which discharge of antimicrobial resistant bacteria into the environment contributes to the dissemination of antimicrobial resistance is uncertain because studies are always limited to antimicrobial resistance in bacteria in the environment [39] and [48-50]. Antimicrobial resistant bacteria may be discharged into the environment from human sources (hospital and municipal effluents), agricultural sources and industrial sources (pharmaceutical wastewaters) [51-54]. This study has shown that amoxicillinclavulanate and colistin resistant $\mathrm{C}$. sakazakii strain are present in the environment in Nigeria. Most previous studies of the antibiotic resistance profile of pathogenic bacteria have been directed towards clinical isolates. There is a possibility that antibiotic resistance genes in C. sakazakii strains in this study could have opportunities for environmental dissemination and possible human exposure and transmission.

At present, antibiotic treatment is a primary preference, and in many cases the only way of treating infectious diseases. More detailed studies of environmental reservoirs of resistance are essential to future ability to combat infections. This is the first report describing amoxicillinclavulanate and colistin resistant identified C. sakazakii strain isolated from industrial wastewaters in Nigeria. Most industries do not have wastewaters treatment facilities, especially in a majority of pharmaceutical industries in Nigeria. Possible remedies could be achieved when treatment measures of the wastewaters are implemented. However urgent mitigation is needed to minimize the effects from the release of pharmaceutical wastewaters to water resources. The potential threat posed by the continued evolution of antibiotic resistance seems sufficiently grave and imminent that reliance upon participant behavioural change should be considered a high-risk strategy. A major drawback to this investigation was haven not gone further to establishing the sequence type of the C. sakazakii strain identified in our study, this is necessary in order to categorically attribute its possible link to the sequence types implicated in clinical strains known to be colonizers or causes of Cronobacter infections in unsuspecting individuals; this is important for the purpose of epidemiological studies.

\section{Conclusion}

In conclusion, this study established the presence of augmentin and colistin resistant $C$. sakazakii in a pharmaceutical wastewater from Nigeria. This bacterium has always been found in PIF, with little information of its presence and susceptibility to antibiotics in wastewaters. The knowledge of the possibility of the existence of this fact reveals possible dissemination of resistant genes into the environment. Therefore, there is the need for further research 
on the continuous surveillance of this bacterium with resistant determinants in the environment in other to help reduce their impact on public health; this calls for great concern.

\section{Acknowledgements}

The authors thank Ivo Steinmetz, Christian Kohler, Katrin Breitbach, André Göhler, Veronica Balau, Anne Kohler, Elsa Baufeld, from Friedrich Loeffler Institute, Greifswald, Germany for their excellent professional and technical assistance.

\section{Funding}

This research received no specific grant from any funding agency in the public, commercial, or not-for-profit sectors.

\section{Competing Financial Interests}

None declared.

\section{Conflict of Interest}

As this work was unfunded, with respect to government and pharmaceutical industry sources, there were no conflicts of interest or undue influence in the preparation of this manuscript.

\section{References}

[1] A. Alsonosi, S. Hariri, M. Kajsík, and et al. The speciation and genotyping of Cronobacter isolates from hospitalised patients. European J. Cli. Microbiol. Infect. Dis. Vol. 34, pp.19791988,2015 .

[2] P. Ogrodzki and S. Forsythe. Capsular profiling of the Cronobacter genus and the association of specific Cronobacter sakazakii and C. malonaticus capsule types with neonatal meningitis and necrotizing enterocolitis. BMC Genomics. doi. org/10.1186/s12864-015-1960-z, 2015.

[3] S. Shukla, G. Lee, X. Song and et al. Detection of Cronobacter sakazakii in powdered infant formula using an immunoliposome-based immunomagnetic concentration and separation assay. Appl. Microbiol. Scientific Reports 6, Article number: 34721, doi:10.1038/srep34721, 2016.

[4] S. J. Forsythe, B. Dickins and K. A. Jolley. Cronobacter, the emergent bacterial pathogen Enterobacter sakazakii comes of age; MLST and whole genome sequence analysis. BMC Genomics. Vol. 15, pp.1121-1122, 2014.

[5] S. Josepha, H. Sonbola, S. Hariria, P. Desaib, M. McClellandb and S. J. Forsythea. Diversity of the Cronobacter Genus as Revealed by Multilocus Sequence Typing. J. Clin. Microbiol. vol. 50(9), pp. 3031-3039, 2012.

[6] V. K. Singamsettya, Y. Wang, H. Shimad and N. V. Prasadaraoac. Outer membrane protein A expression in Enterobacter sakazakii is required to induce microtubule condensation in human brain microvascular endothelial cells for invasion. Microbial Pathogenesis. Vol. 45(3), Pp. 181-191,
2008.

[7] J. van Acker, F. De Smet, G. Muyldermans, A. Bougatef, A. Naessens and S. Lauwers. Outbreak of necrotizing enterocolitis associated with Enterobacter sakazakii in powdered milk formula. J. Clin. Microbiol. Vol. 39, pp. 293297, 2001.

[8] I. Himelright, E. Harris, V. Lorch and M. Anderson. Enterobacter sakazakii infections associated with the use of powdered infant formula - Tennessee, 2001. J. Am. Med. Assoc. Vol. 287, pp.2204-2205, 2002.

[9] J. Caubilla-Barron, E. Hurrell, S. Townsend and et al. Genotypic and phenotypic analysis of Enterobacter sakazakii strains from an outbreak resulting in fatalities in a neonatal intensive care unit in France. J. Clin. Microbiol. Vol. 45, pp. 3979-3985, 2007.

[10] M. Nazarowec-White and J. M. Farber. Enterobacter sakazakii: Int. J. Food. Microbiol. Review. Vol. 34, pp.103113, 1997a.

[11] J. B. Gurtler, J. L. Kornacki and L. R. Beuchat. Enterobacter sakazakii: a coliform of increased concern to infant health. Int. J. Food. Microbiol. Vol. 104, pp. 1-34, 2005

[12] N. Singh, G. Goel and M. Raghav. Insights into virulence factors determining the pathogenicity of Cronobacter sakazakii. J. Virulence, Vol. 6 (5), pp. 433-440, 2015.

[13] S. Joseph and S. J. Forsythe. Predominance of Cronobacter sakazakii sequence type 4 in neonatal infections. Emerg. Infect. Dis. Vol. 17: pp. 1713-1715, 2011.

[14] S. Joseph, H. Sonbol, S, Hariri, P. Desai, M. McClelland and S. J. Forsythe. Diversity of the Cronobacter genus as revealed by multilocus sequence typing. J. Clin. Microbiol. Vol. 50, pp. 3031-3039, 2012c.

[15] P. Fei, Y, Jiang, Y. Jiang and et al. Prevalence, molecular characterization, and antibiotic susceptibility of Cronobacter sakazakii Isolates from powdered infant formula collected from Chinese retail markets. Front. Microbiol. Vol. 8, pp. 2026. doi: 10.3389/fmicb.2017.

[16] H. R. Chase, G. R. Gopinath, A. K. Eshwar and et al. Comparative genomic characterization of the highly persistent and potentially virulent Cronobacter sakazakii ST83, CC65 strain H322 and other ST83 strains. Front. Microbiol. Vol. 8, pp. 1136-1137, 2017.

[17] H. Sonbol, S. Joseph, C. M. McAuley, H. M. Craven and S. J. Forsythe. Multilocus sequence typing of Cronobacter spp. from powdered infant formula and milk powder production factories. Int. Dairy. J. Vol. 30, pp. 1-7, 2013.

[18] F. Depardieu, I. Podglajen, R. Leclercq and et al. Modes and modulations of antibiotic resistance gene expression. Clin. Microbiol. Rev. Vol. 20, pp.79-114 2007.

[19] R. L. Finley, P. Collingnon, D. G. Joakim Larsson and et al. The scourge of antibiotic resistance: The important role in the environment. Clin. Infect. Dis. Rev. Vol. 355, pp.1-7, 2013.

[20] A. P. Magiorakos, A. Srinivason, R. B. Carey and et al. Multidrug-resistant, extensively drug-resistant and pandrugresistant bacteria: an international expert proposal for interim standard definitions for acquired resistance. Eur. Soc. Clin. Microbiol. Infect. Dis. Vol.18, pp. 268 -281, 2011. 
[21] H. Yoneyama and R. Katsumata. Antibiotic resistance in bacteria and its future for novel antibiotic development. Biosci. Biotechnol. Biochem. Vol. 70, pp.1060-1075, 2006.

[22] M. A. S, McMahon, J. Xu, J. E. Moore, I. S. Blair and D. A. McDowell. Environmental stress and antibiotic resistance in food-related pathogens. Appl. Environ. Microbiol. Vol. 73, pp. 211-117, 2007.

[23] J. W. Chenu and J. M. Cox. Cronobacter ('Enterobacter sakazakii'): current status and future prospects. A review. The Society for Applied Microbiology, Letters Appl. Microbiol. Vol. 49, pp. 153-159, 2009.

[24] S. Y. Park, M. F. R. Mizan and S. DoHa. Inactivation of Cronobacter sakazakii in head lettuce by using a combination of ultrasound and sodium hypochlorite. Food Control. Vol. 60, pp. 582-587, 2016.

[25] M. Nazarowec-White and J. M. Farber. Incidence, survival, and growth of Enterobacter sakazakii in infant formula. J. Food. Prot. Vol. 60, pp. 226-230, 1997c.

[26] C. Iversen and S. Forsythe. Isolation of Enterobacter sakazakii and other Enterobacteriaceae from powdered infant formula milk and related products. Food Microbiol. Vol. 21, pp. 771-777, 2004.

[27] N. R. Mullane, P. Whyte, P. G. Wall, T. Quinn and S. Fanning. Application of pulsed-field gel electrophoresis to characterize and trace the prevalence of Enterobacter sakazakii in an infant formula processing facility. Int. J. Food Microbiol. Vol. 116, pp. 73-81, 2007.

[28] A. A. Bakare, M. M. Ademeso, O. A. Adetunji and O. A. Alabi. Pharmaceutical effluent induced chromosome aberration in rat bone marrow cells. Arch. Appl. Sci. Res. Vol. 3, No. 2, pp. 345-52, 2011.

[29] N. C. Ngwuluka, N. A. Ochekpe and P. O. Odumosu. An assessment of pharmaceutical waste management in some Nigerian pharmaceutical industries. Afri. J. Biotechnol. Vol. 10, No. 54, pp. 11259-1268, 2011.

[30] P. K. Talaro. Foundations in Microbiology. San Francisco: Pearson Benjamin Cummings. Pp. 24-25, 2009.

[31] M. Asthana, A. Kumar and B. S. Sharma. Principles and Applications of Environmental Biotechnology for a Sustainable Future. Appl. Env. Sci. Engr. for a Sustainable Future book series (AESE), pp. 173-232, 2016.

[32] D. T. John, H. J. James, P. R. Murray and et al. Manual of Clinical Microbiology (7th ed.), Washington D. C.: American Society for Microbiology. Pp. 302-305, 2009.

[33] A. Kola, C. Kohler, Y. Pfeifer and et al. High prevalence of extended spectrum beta-lactamase-producing Enterobacteriaceae in organic and conventional retail chicken meat, Germany. J. Antimicrob. Chemother. Vol. 67, pp. 2631634, 2012.

[34] B. A Forbes, D. F. Sahm and A. S. Weissfeld. Bailey \& Scott's Diagnostic Microbiology-E-Book, Elsevier Health Sciences, Twelfth edition, 2015.

[35] European Committee on Antimicrobial Susceptibility Testing (EUCAST). Breakpoint tables for interpretation of MICs and zone diameters. 2013; Verson 3.1. http://www.eucast.org.

[36] W. R. Abraham. Megacities as sources of pathogenic bacteria in rivers and their fate downstream. Int. J. Microbiol. Article ID 798292. dio: 10.1155/2011/798292; 13 pages, 2011.

[37] R. M. Kent, G. F. Fitzgerald, C. Hill, C. Stanton and R. P. Ross. Novel Approaches to Improve the Intrinsic Microbiological Safety of Powdered Infant Milk Formula. Nutrients Vol. 7(2), 1217-1244, 2015.

[38] W. H. Gaze, S. M. Krone, D. G. Joakim-Larsson and et al. Influence of humans on evolution and mobilization of elemental antibiotic resistome. Centers Dis. Cont. Prev. Vol. 19, No. 7, pp. 1-10, 2013.

[39] S. Galvin, F. Boyle, P. Hickey, A. Vellinga, D. Morris and C. M. Martin. Enumeration and characterization of antimicrobialresistant Escherichia coli bacteria in effluent from municipal, hospital, and secondary treatment facility sources. Appl. Environ. Microbiol. Vol. 76, pp. 4772-4779, 2010.

[40] C. Molloy, C. Cagney, S. O'Brien, C. Iversen, S. Fanning and G. Duffy. Surveillance and characterisation by pulsed-field gel electrophoresis of Cronobacter spp. in farming and domestic environments, food production animals and retail foods. Int. J . Food Microbiol. Vol. 136, pp. 198-203, 2009.

[41] Y. Ye, Q. Wu, X. Xu, X. Yang, X. Dong and J. Zhang. The phenotypic and genotypic characterization of Enterobacter sakazakii strains from infant formula milk. J. Dairy Sci. Vol. 93, pp. 2315-2320, 2010.

[42] J. W. Chon, K. Y. Song, S. Y. Kim, J. Y. Hyeon and K. H. Seo. Isolation and characterization of Cronobacter from desiccated foods in Korea. J. Food Sci. Vol. 77, pp. 354-358, 2012.

[43] Y. D. Lee, J. H. Park and H. I. Chang. Detection, antibiotic susceptibility and biofilm formation of Cronobacter spp. from various foods in Korea. Food Contrl. Vol. 24, pp. 225-230, 2012.

[44] Z. Pan, J. Cui, G. Lyu and et al. Isolation and molecular typing of Cronobacter spp. in commercial powdered infant formula and follow-up formula. Foodborne Pathog. Dis. Vol. 11, pp. 456-461, 2014.

[45] Enterobacter Infections Treatment \& Management: Medical Care, Surgical Care, Consultations. Medical Care Antimicrobial therapy is indicated in virtually all Enterobacter infections. https://emedicine.medscape.com/article/216845treatment last visited Feb., 2018

[46] A. Lehner and R. Stephan. Microbiological, epidemiological, and food safety aspects of Enterobacter sakazakii. J. Food Prot. Vol. 67, pp. 2850-2857, 2004.

[47] A. Ahmed, A. Azim, M. Gurjar and A. K. Baronia. Current concepts in combination antibiotic therapy for critically ill patients. Peer-reviewed, Official publication of Indian Society of Critical Care medicine. Indian J. Crit. Care med. Vol. 18, No. 5), pp. 310-314, 2014.

[48] M. Ferreira da silva, I. Vaz-Moreira, M. Gonzalez-Pajuoelo, O. C. Nunes and C. M. Manaia. Antimicrobial resistance patterns in Enterobacteriaceae isolated from an urban wastewater treatment plant. FEMS Microbiol. Ecol. 2007; Vol. 60, pp. 166-176, 2007.

[49] X. A. Vilanova, M. Manera, C. Cerda and A. R. Blanch. The composition and persistence of faecal coliforms and enterococccal populations in sewage treatment plants. J. Appl. Microbiol. Vol. 96, pp. 279-288, 2004. 
[50] S. Bergeron, R. Boopathy, R. Nathaniel, A. Corbin, G. LaFleur. Presence of antibiotic resistant bacteria and antibiotic resistance genes in raw source water and treated drinking water. Internl Biodeterio. Biodeg. Vol. 102, Pp. 370-374, 2015.

[51] A. Mechai, M. Debabza, H. Sedira, S. Fadeleddine and A. Mechai. Extended-Spectrum Beta-lactamases-Producing Enterobacteriaceae Isolated from a River Water Receiving an Effluent Treatment Plant. Euro-Mediterranean Conference for Environmental Integration (EMCEI), pp. 1933-1934, 2017.

[52] R. J. Mesa, A. R. Blanc, P. Cortes and et.al. Extended spectrum Beta-lactamase producing Enterobacteriaceae in different environments (human, food, animal farms and sewage). J. Antimicrob. Chemother. Vol. 58, pp. 211-215, 2006.
[53] R. J. Aziz, F. S. Al-Zubaidy, H. J. Al-Mathkhury, B. Resul and J. Musenga. Antibiogram of Escherichia coli Isolated from different Hospitals Wastewater in Erbil City, Iraq. Iraqi Journal of Science, Vol. 55(2A), pp. 341-351, 2014.

[54] A. Obasi, S. Nwachukwu, E. Ugoji and et al. Extended Spectrum $\beta$-Lactamase-Producing Klebsiella pneumoniae from Pharmaceutical Wastewaters in South-Western Nigeria. Microbl. Drug Res. DOI: 10.1089/mdr.2016.0269. 2017. 